\title{
Violência doméstica contra mulheres e meninas no estado de Sergipe: uma questão de saúde pública
}

\author{
Domestic violence against women and girls in the state of Sergipe: a public health matter \\ Violencia doméstica contra mujeres y niñas en el estado de Sergipe: un problema de salud pública
}

Recebido: 12/01/2022 | Revisado: 19/01/2022 | Aceito: 05/02/2022 | Publicado: 07/02/2022

\author{
Rafael Rocha de Araújo \\ ORCID: https://orcid.org/0000-0002-5336-0507 \\ Universidade Federal de Sergipe, Brasil \\ E-mail: rafaelrocha.92.rr@gmail.com \\ Arthur Oliveira da Cruz \\ ORCID: https://orcid.org/0000-0001-6961-6418 \\ Universidade Federal de Sergipe, Brasil \\ E-mail: oarthurcruz@gmail.com \\ João Eduardo Andrade Tavares de Aguiar \\ ORCID: https://orcid.org/0000-0002-9576-8148 \\ Universidade Federal de Sergipe, Brasil \\ E-mail: joaoeduardoandrade97@ gmail.com \\ Marcos Antônio Lima Carvalho \\ ORCID: https://orcid.org/0000-0002-3543-2028 \\ Universidade Federal de Sergipe, Brasil \\ E-mail: marcoslimac27@gmail.com \\ Aline Rocha Aguiar \\ ORCID: https://orcid.org/0000-0002-3309-5945 \\ Universidade Federal de Sergipe, Brasil \\ E-mail: alineaguiar96@yahoo.com \\ Vitória Teles Apolônio Santos \\ ORCID: https://orcid.org/0000-0002-4876-3512 \\ Universidade Federal de Sergipe, Brasil \\ E-mail: vitoria.apolonio@gmail.com \\ Thaís Serafim Leite de Barros Silva \\ ORCID: https://orcid.org/0000-0003-1696-6507 \\ Universidade Federal de Sergipe, Brasil \\ E-mail: thaisserafim@hotmail.com \\ Júlia Maria Gonçalves Dias \\ ORCID: https://orcid.org/0000-0001-9145-5534 \\ Universidade Federal de Sergipe, Brasil \\ E-mail: dias_jmg@yahoo.com.br
}

\begin{abstract}
Resumo
A violência doméstica contra a mulher é definida na Lei Maria da Penha como qualquer ação ou omissão baseada no gênero que lhe cause morte, lesão, sofrimento físico, sexual ou psicológico. O presente trabalho objetivou caracterizar o perfil da violência doméstica em Sergipe no período de 2009 a 2019, através de dados secundários de notificação compulsória. Foram analisadas variáveis referentes à vítima, ao agressor e à a ocorrência. Nas 4.997 notificações, prevaleceu mulheres de 20 a 59 anos $(45,0 \%)$, da cor parda (44,8\%) e com escolaridade entre 5 a 8 anos de estudo $(13,3 \%)$. O local foi a residência da vítima (50,8\%), os agressores amigos/conhecidos (15,6\%), com taxa de reincidência de $29,1 \%$ e elevada suspeita de consumo de álcool pelo agressor (23,8\%). As violências física e sexual $(53,2$ e $41,6 \%)$ tiveram destaque; com o uso de força corporal como meio de violência (44,3\%) e o estupro o principal tipo de violência sexual (80,3\%). A qualidade da informação das notificações é muito discutível, visto que muitas variáveis são mal preenchidas. A falta de informações precisas prejudica o conhecimento do fenômeno, interferindo nas ações de combate e planejamento dos serviços de saúde, sendo necessário um melhor preparo dos profissionais que lidam com essas situações.
\end{abstract}

Palavras-chave: Violência doméstica; Violência contra a mulher; Notificação compulsória.

\begin{abstract}
Domestic violence against women is defined in the Maria da Penha Law as any action or omission based on gender that causes death, injury, physical, sexual or psychological suffering. The present study aimed to characterize the profile of domestic violence in Sergipe in the period from 2009 to 2019, through secondary data of compulsory notification. Variables related to the victim, the aggressor and the occurrence were analyzed. In the 4,997
\end{abstract}


notifications, women aged 20 to 59 years $(45.0 \%)$, parda $(44.8 \%)$ and with level of education between 5 and 8 years of study $(13.3 \%)$ prevailed. The place of occurrence was the residence of the victim $(50.8 \%)$, the aggressors were friends/acquaintances $(15.6 \%$ ), with recidivism rate of $29.1 \%$ and high suspicion of alcohol consumption by the aggressor (23.8\%). Physical and sexual violence (53.2 and 41.6\%) were highlighted; with the use of corporal force as a means of violence $(44.3 \%)$ and rape, the main type of sexual violence $(80.3 \%)$. The quality of reporting information is debatable since many variables are poorly filled out. The lack of precise information impairs the knowledge of the phenomenon, interfering in the actions of combat and planning of the health services, being necessary a better preparation of the professionals that deal with these situations.

Keywords: Domestic violence; Violence against women; Mandatory reporting.

\section{Resumen}

La violencia doméstica contra la mujer se define en la Ley Maria da Penha como cualquier acción u omisión basada en el género que cause muerte, lesiones, sufrimiento físico, sexual o psicológico. Este estudio tuvo como objetivo caracterizar el perfil de la violencia intrafamiliar en Sergipe de 2009 a 2019 a través de datos secundarios de notificación obligatoria. Se analizaron variables relacionadas con la víctima, el agresor y el hecho. En las 4.997 notificaciones predominaron las mujeres de 20 a 59 años (45,0\%), pardas $(44,8 \%)$ y con escolaridad entre 5 y 8 años de estudio (13,3\%). El lugar fue el domicilio de la víctima (50,8\%), los agresores fueron amigos/conocidos (15,6\%), con una tasa de reincidencia del $29,1 \%$ y alta sospecha de consumo de alcohol por parte del agresor $(23,8 \%)$. Se destacó la violencia física y sexual (53,2 y 41,6\%); con el uso de la fuerza física como medio de violencia (44,3\%) y la violación como principal tipo de violencia sexual $(80,3 \%)$. La calidad de la información en las notificaciones es muy discutible, ya que muchas variables están mal llenas. La falta de información veraz perjudica el conocimiento del fenómeno, interfiriendo con las acciones de combate y planificación de los servicios de salud, requiriendo una mejor preparación de los profesionales que enfrentan estas situaciones.

Palabras clave: Violencia doméstica; Violencia contra la mujer; Notificación obligatoria.

\section{Introdução}

A violência doméstica contra a mulher é definida na Lei Maria da Penha (Lei nº 11.340, de 7 de agosto de 2006) como qualquer ação ou omissão baseada no gênero que lhe cause morte, lesão, sofrimento físico, sexual ou psicológico e dano moral ou patrimonial (Brasil, 2006). A Lei tem esse nome em homenagem à farmacêutica cearense Maria da Penha Maia Fernandes que, em 1983, sofreu duas tentativas de homicídio por parte do seu marido. Após sair de casa com suas filhas e buscar ajuda, só conseguiu vê-lo punido 19 anos depois, com uma condenação de 10 anos de prisão, dos quais somente dois foram cumpridos em regime fechado. Em protesto, diversas manifestações de movimentos feministas foram organizadas no país, resultando na realização de audiências públicas pela Câmara dos Deputados e a consequente aprovação da Lei. Nesse sentido, o país tem o intuito de oferecer às mulheres uma ferramenta de proteção contra a violência, não somente no âmbito familiar, ao passo em que combate também a impunidade dos agressores (Brasil, 2010).

Os atentados à mulher partem principalmente de maridos, pais e filhos, seguidos por namorados, ex-namorados e conhecidos. Nessas situações as lesões corporais e maus tratos variam muito quanto à classificação, agente causador, local e idade das vítimas (Garbin et al., 2006). Do ponto de vista da saúde, os danos às vítimas se dão através de mecanismos diretos e indiretos de agressão que levam a traumas e sequelas resultantes do espancamento, bem como o estresse psicológico crônico, depressão e baixa autoestima (Garbin et al., 2006; Miranda et al., 2010). Casos de óbito também são muito comuns, caracterizando a expressão máxima da violência contra a mulher, o que tem levado o movimento feminista a empregar o termo "feminicídio" para referir-se à morte de uma mulher causada por um homem em razão de conflito de gênero (Garcia et al., 2015).

As consequências desse tipo de violência afetam diversos segmentos da sociedade, desequilibrando as esferas econômica, emocional e familiar, caracterizando a violência doméstica como a forma mais comum de maus tratos contra a mulher e, dessa forma, devendo ser detectada pelo profissional de saúde e encarada como questão de saúde pública (Garbin et al., 2006). Este cenário é ainda mais alarmante em função da recorrência dos casos, resultando em um alto impacto socioeconômico ao gerar gastos em cuidados à saúde física e mental das pacientes, além da perda de produtividade das vítimas não fatais (Miranda et al., 2010). 
Anteriormente à Lei Maria da Penha, na Lei de n ${ }^{\circ}$ 10.778, de 24 de dezembro de 2003, foi estabelecida a notificação compulsória dos casos de violência contra a mulher sofridos por vítimas atendidas em serviços de saúde públicos ou privados (Brasil, 2003). Os profissionais de saúde, principalmente na atenção primária, têm um importante papel na detecção precoce desse problema, entretanto os médicos de família apresentam um baixo envolvimento nesse processo, seja por treinamento insuficiente, falta de habilidades gerenciais, medo das implicações legais, resistência ao reconhecimento do papel do profissional quanto à violência de gênero, dentre outras causas (Alonso, 2015). Apesar disso, a intervenção nas situações de violência cabe a todos que atuam nesses setores e eles devem ser preparados para atender esse tipo de usuária (Garbin et al., 2006).

Sendo um agravo de notificação compulsória, as informações sobre violência doméstica possuem uma ficha própria que deve ser preenchida pelo profissional que suspeite ou confirme o caso de violência e encaminhado aos serviços responsáveis pela informação e/ou vigilância epidemiológica das Secretarias Municipais e Estaduais. Essas informações abastecem o Sistema de Informação de Agravos de Notificação (SINAN), parte do Departamento de Informática do Sistema Único de Saúde (DATASUS), que tem como objetivo o registro e processamento desses dados e análise do perfil de morbidade, contribuindo para a tomada de decisões em nível municipal, estadual e federal (Ferraz, 2009). Entretanto, esse sistema de informação está em constante modificação e, algumas vezes, não permite sua utilização em uma análise mais profunda acerca de determinados dados a longo prazo, sendo também pouco comum sua aplicação em trabalhos científicos (Vasconcelos et al., 2002). Nesse sentido, considerando a relevância da violência contra a mulher como um problema de saúde pública e a importância do SINAN como ferramenta de notificação, torna-se necessário o uso de seus dados em mais trabalhos que fomentem o debate sobre o tema e busquem soluções para a questão.

Para tal, o presente trabalho tem como objetivo caracterizar o perfil da violência doméstica contra mulheres em Sergipe, no período de 2009 a 2019, através do uso de dados de notificação compulsória do SINAN, disponíveis na base de dados do DATASUS. A partir dessas informações será possível identificar as formas mais comuns de violência doméstica no estado e definir o perfil da vítima e do agressor, assim como o desfecho de evolução e encaminhamento desses casos.

\section{Metodologia}

O presente trabalho tem caráter descritivo e retrospectivo e realizou o levantamento e apreciação dos dados referentes aos casos de violência doméstica contra a mulher no estado de Sergipe disponíveis no Sistema de Informação de Agravos e Notificação - SINAN (Brasil, 2021a). Esse tipo de ferramenta de dados públicos permite a identificação da realidade epidemiológica de agravos e doenças de notificação compulsória como a violência doméstica. Seu uso sistemático e descentralizado permite que os profissionais da saúde tenham acesso a informação e tornem disponíveis para a comunidade, além de auxiliar o planejamento e definir prioridades de intervenção.

A coleta dos dados ocorreu no período de junho a setembro de 2021 através da seleção de variáveis da Ficha de Notificação Compulsória de Violência Doméstica, Sexual e Outras Violências Interpessoais, disponíveis no website do DATASUS (Brasil, 2021a; Brasil, 2021b). Os dados são referentes aos casos de vítimas do sexo feminino entre os anos de 2009 e 2019 notificados no estado de Sergipe. Para evitar algum tipo de viés nas informações obtidas, os dados foram filtrados a partir das próprias ferramentas do DATASUS com o objetivo de excluir os casos de violência sobre a forma de lesões autoprovocadas pelas pacientes.

Embora nem todas as variáveis da Ficha de Notificação estejam disponíveis para domínio público, a base de dados do DATASUS fornece informações variáveis importantes que foram avaliadas nesse trabalho. Foram elas: faixa etária, raça e escolaridade, local da ocorrência, violência de repetição, meio da agressão e tipos de violência, tipos de violência sexual; relação da a pessoa atendida com o autor da agressão e suspeita de uso de álcool pelo agressor; encaminhamento e evolução do 
caso. Os mesmos foram apresentados em frequência absoluta e relativa, através da confecção de tabelas e gráficos com o auxílio do software Microsoft Excel®.

Por se tratarem de dados secundários da base de informações do SUS de livre acesso, o presente estudo não possui restrições éticas para sua condução e não precisou de apreciação de um Comitê de Ética em Pesquisa para sua condução. As informações pessoais das vítimas não são disponíveis, garantindo o anonimato e a confidencialidade das informações, conforme diretrizes da Resolução nº 466, de 2012, do Conselho Nacional de Saúde.

\section{Resultados}

Durante o período de 2009 a 2019, foram registradas 4.997 notificações de violência doméstica, sexual e outras violências contra mulheres e meninas no estado de Sergipe. Esse número corresponde a 77,3\% do total de 6.468 casos de violência doméstica no estado nesse mesmo período (Figura 1).

Figura 1. Distribuição percentual das notificações de violência doméstica, sexual e outras violências segundo sexo. Sergipe, 2009 a $2019(\mathrm{~N}=6.468)$.

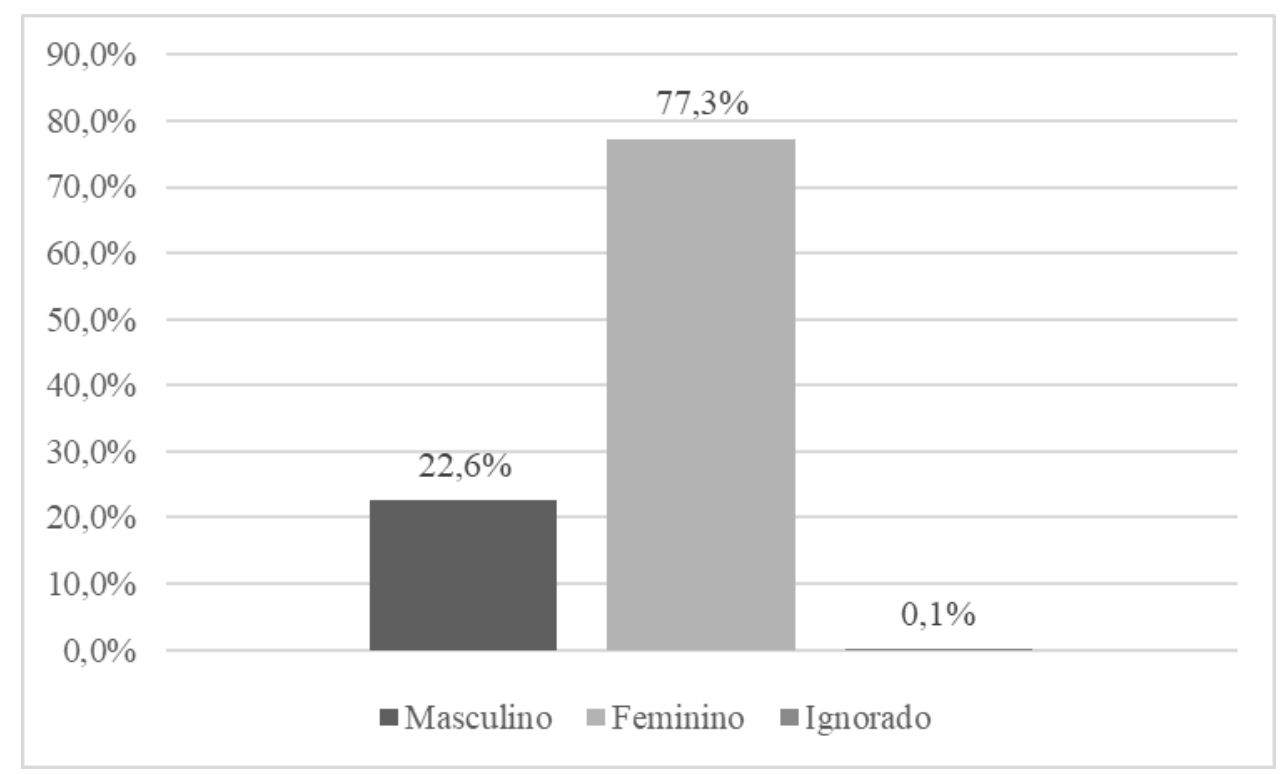

Fonte: Ministério da Saúde/SVS - Sistema de Informação de Agravos de Notificação (SINAN) (2021).

Das 4.997 notificações do sexo feminino, 2.247 (45,0\%) são mulheres adultas de 20 a 59 anos, 1.460 (29,2\%) estão na faixa etária de 10 a 19 anos, 1.083 (21,7\%) são meninas menores de 10 anos, 200 (4,0\%) são idosas maiores de 60 anos e 7 indivíduos $(0,1 \%)$ com idade ignorada. Quanto à raça, 2.237 mulheres $(44,8 \%)$ se declararam pardas, $544(10,9 \%)$ brancas, 350 (7,0\%) pretas e uma grande parcela de 1.825 (36,5\%) não tinham essa informação disponível. O nível de escolaridade foi um parâmetro que teve suas informações ignoradas ou não declaradas em sua maioria, sendo 2.472 (49,5\%) casos sem essa informação, além de $801(16,0 \%)$ casos em que a variável não se aplicava por se tratar de menores de 10 anos. As analfabetas corresponderam a apenas $71(1,4 \%)$ das notificações, enquanto $524(10,5 \%)$ mulheres tinham estudado da $1^{\mathrm{a}}$ a $4^{\mathrm{a}}$ série do ensino fundamental completa ou incompleta, $665(13,3 \%)$ tinham $5^{\mathrm{a}}$ a $8^{\mathrm{a}}$ série completa ou incompleta, enquanto apenas 362 (7,2\%) possuíam ensino médio completo ou incompleto e 102 (2,0\%) apresentam ensino superior completo ou incompleto no momento da notificação (Tabela 1).

É possível destacar o principal local de ocorrência como sendo a residência da vítima, representando 2.540 (50,8\%) dos casos, seguido de via pública $(9,4 \%)$ e outros lugares $(6,2 \%)$, sendo que boa parte das fichas de notificação não tinham 
informações do local da ocorrência (29,5\%). Ainda na Tabela 1, observamos que $1.454(29,1 \%)$ dos casos eram um caso repetido de violência, enquanto $1.536(30,7 \%)$ não eram violência de repetição, além da importante parcela de 40,2\% dos casos que possuíam informações em branco ou ignoradas.

Tabela 1. Distribuição do número e percentual das notificações de violência doméstica, sexual e outras violências contra indivíduos do gênero feminino em Sergipe, entre 2009 e 2019, de acordo com variáveis da ficha de notificação compulsória do SINAN.

\begin{tabular}{|c|c|c|}
\hline Variáveis & Frequência & $\%$ \\
\hline \multicolumn{3}{|l|}{ Faixa etária } \\
\hline$<10$ anos & 1.083 & 21,7 \\
\hline 10 a 19 anos & 1.460 & 29,2 \\
\hline 20 a 59 anos & 2.247 & 45,0 \\
\hline 60 anos ou mais & 200 & 4,0 \\
\hline Ignorado/Em branco & 7 & 0,1 \\
\hline \multicolumn{3}{|l|}{ Raça } \\
\hline Branca & 544 & 10,9 \\
\hline Preta & 350 & 7,0 \\
\hline Amarela & 38 & 0,8 \\
\hline Parda & 2.237 & 44,8 \\
\hline Indígena & 3 & 0,1 \\
\hline Ignorado/Em branco & 1.825 & 36,5 \\
\hline \multicolumn{3}{|l|}{ Escolaridade } \\
\hline Analfabeto & 71 & 1,4 \\
\hline $1^{\mathrm{a}}$ a $4^{\mathrm{a}}$ série do $\mathrm{EF}^{1}$ incompleta ou completa & 524 & 10,5 \\
\hline $5^{\mathrm{a}}$ a $8^{\mathrm{a}}$ série do $\mathrm{EF}^{1}$ incompleta ou completa & 665 & 13,3 \\
\hline Ensino médio incompleto ou completo & 362 & 7,2 \\
\hline Educação superior incompleto ou completo & 102 & 2,0 \\
\hline Ignorado/Em branco & 2.472 & 49,5 \\
\hline Não se aplica* & 801 & 16,0 \\
\hline \multicolumn{3}{|l|}{ Local de ocorrência } \\
\hline Residência/Habitação coletiva & 2.540 & 50,8 \\
\hline Via pública & 469 & 9,4 \\
\hline Bar ou similar & 80 & 1,6 \\
\hline Escola & 57 & 1,1 \\
\hline Comércio/Serviços/Indústrias/Construção & 57 & 1,1 \\
\hline Local de prática esportiva & 10 & 0,2 \\
\hline Outros & 309 & 6,2 \\
\hline Ignorado/Em branco & 1.475 & 29,5 \\
\hline \multicolumn{3}{|l|}{ Violência de repetição } \\
\hline Sim & 1.454 & 29,1 \\
\hline Não & 1.536 & 30,7 \\
\hline Ignorado/Em branco & 2.007 & 40,2 \\
\hline
\end{tabular}

*Todos os casos assinalados como "Não se aplica" na variável "Escolaridade" foram de indivíduos menores de 10 anos; ${ }^{1} \mathrm{EF}=\mathrm{Ensino}$ Fundamental. Fonte: Ministério da Saúde/SVS - Sistema de Informação de Agravos de Notificação (SINAN) (2021).

Quanto à tipologia, foram 2.659 (53,2\%) casos de violência física, 2.078 (41,6\%) casos de violência sexual, 961 (19,2\%) notificações de violência psicológica/moral, além de $518(10,4 \%)$ relatos de negligência ou abandono. Quanto aos meios de execução da agressão, foram encontrados 2.216 (44,3\%) casos de uso de força corporal, 524 (10,5\%) relatos de ameaça, 274 (5,5\%) usaram arma branca, 189 (3,8\%) objeto contundente e $156(3,1 \%)$ arma de fogo. Nos casos de violência sexual as denúncias de estupro tiveram destaque com $1.682(80,3 \%)$ casos, seguido de outras violências sexuais (7,0\%), assédio sexual $(4,7 \%)$ e atentado violento ao pudor $(2,1 \%)$ (Tabela 2$)$.

É importante destacar que as taxas de notificações ignoradas ou em branco são expressivas em todas as variáveis 
observadas até agora. Quanto à tipologia de violência, as variáveis sem informação variaram de 3,8\% a 14,5\%. O meio de agressão foi mais subnotificado, com dados incompletos variando de $20,8 \%$ a 25,8\%. Por fim, nos casos de violência sexual essas lacunas no preenchimento da ficha variaram de 9,6\% nos casos de estupro até 74,5\% nos casos de atentado violento ao pudor (Tabela 2).

Em relação aos principais suspeitos de serem autores dos casos de violência doméstica, em primeiro lugar ficaram os amigos/conhecidos, com 15,6\% dos casos, seguidos de cônjuge (11,3\%), desconhecidos $(9,7 \%)$, outros vínculos (7,6\%), pai $(6,6 \%)$, mãe $(6,0 \%)$, padrasto $(4,6 \%)$ e namorado(a) $(4,5 \%)$ (Tabela 2$)$.

Tabela 2. Tipologia, meios de execução e relação do agressor com a vítima em casos de violência contra a mulher em Sergipe, entre 2009 e 2019, de acordo com variáveis da ficha de notificação compulsória do SINAN.

\begin{tabular}{|c|c|c|c|c|c|c|c|}
\hline \multirow{2}{*}{$\begin{array}{l}\text { Variáveis } \\
\text { Tipos de Violência }\end{array}$} & \multicolumn{2}{|c|}{ Sim } & \multicolumn{2}{|c|}{ Não } & \multicolumn{2}{|c|}{ Ignorado } & \multirow[t]{2}{*}{ Total } \\
\hline & & & & & & & \\
\hline Violência Física & 2.659 & $53,2 \%$ & 1.839 & $36,8 \%$ & 499 & $10,0 \%$ & 4.997 \\
\hline Violência Psicológica/Moral & 961 & $19,2 \%$ & 3.531 & $70,7 \%$ & 505 & $10,1 \%$ & 4.997 \\
\hline Negligência/Abandono & 518 & $10,4 \%$ & 3.954 & $79,1 \%$ & 525 & $10,5 \%$ & 4.997 \\
\hline Violência Sexual & 2.078 & $41,6 \%$ & 2.731 & $54,6 \%$ & 188 & $3,8 \%$ & 4.997 \\
\hline Tráfico de Seres Humanos & 5 & $0,1 \%$ & 4.375 & $87,6 \%$ & 617 & $12,3 \%$ & 4.997 \\
\hline Trabalho Infantil & 4 & $0,1 \%$ & 4.372 & $87,5 \%$ & 621 & $12,4 \%$ & 4.997 \\
\hline Tortura & 76 & $1,5 \%$ & 4.298 & $86,0 \%$ & 623 & $12,5 \%$ & 4.997 \\
\hline Violência Patrimonial & 62 & $1,2 \%$ & 4.318 & $86,4 \%$ & 617 & $12,3 \%$ & 4.997 \\
\hline Violência por Intervenção Legal & 8 & $0,2 \%$ & 4.354 & $87,1 \%$ & 635 & $12,7 \%$ & 4.997 \\
\hline Outros Tipos de Violência & 29 & $0,6 \%$ & 4.242 & $84,9 \%$ & 726 & $14,5 \%$ & 4.997 \\
\hline \multicolumn{8}{|l|}{ Meio de Agressão } \\
\hline Arma Branca & 274 & $5,5 \%$ & 3.572 & $71,5 \%$ & 1.151 & $23,0 \%$ & 4.997 \\
\hline Arma de Fogo & 156 & $3,1 \%$ & 3.708 & $74,2 \%$ & 1.133 & $22,7 \%$ & 4.997 \\
\hline Objeto Contundente & 189 & $3,8 \%$ & 3.639 & $72,8 \%$ & 1.169 & $23,4 \%$ & 4.997 \\
\hline Força Corporal & 2.216 & $44,3 \%$ & 1.739 & $34,8 \%$ & 1.042 & $20,8 \%$ & 4.997 \\
\hline Enforcamento/Sufocação & 107 & $2,1 \%$ & 3.724 & $74,5 \%$ & 1.166 & $23,3 \%$ & 4.997 \\
\hline Queimadura & 19 & $0,4 \%$ & 3.810 & $76,2 \%$ & 1.168 & $23,4 \%$ & 4.997 \\
\hline Envenenamento & 17 & $0,3 \%$ & 3.811 & $76,3 \%$ & 1.169 & $23,4 \%$ & 4.997 \\
\hline Ameaça & 524 & $10,5 \%$ & 3.375 & $67,5 \%$ & 1.098 & $22,0 \%$ & 4.997 \\
\hline Outros Meios de Agressão & 184 & $3,7 \%$ & 3.521 & $70,5 \%$ & 1.292 & $25,8 \%$ & 4.997 \\
\hline \multicolumn{8}{|l|}{ Tipos de Violência Sexual* } \\
\hline Estupro & 1.682 & $80,3 \%$ & 211 & $10,1 \%$ & 202 & $9,6 \%$ & 2.095 \\
\hline Assédio Sexual & 98 & $4,7 \%$ & 1.416 & $67,7 \%$ & 578 & $27,6 \%$ & 2.092 \\
\hline Atendado Violento ao Pudor & 75 & $2,1 \%$ & 844 & $23,4 \%$ & 2.690 & $74,5 \%$ & 3.609 \\
\hline Pornografia Infantil & 9 & $0,4 \%$ & 1.483 & $70,8 \%$ & 601 & $28,7 \%$ & 2.093 \\
\hline Exploração Sexual & 51 & $2,4 \%$ & 1.437 & $68,7 \%$ & 605 & $28,9 \%$ & 2.093 \\
\hline Outras Violências Sexuais & 147 & $7,0 \%$ & 1.337 & $63,9 \%$ & 609 & $29,1 \%$ & 2.093 \\
\hline \multicolumn{8}{|l|}{ Relação com a Vítima } \\
\hline Pai & 328 & $6,6 \%$ & 2.941 & $58,9 \%$ & 1.728 & $34,6 \%$ & 4.997 \\
\hline Mãe & 299 & $6,0 \%$ & 2.955 & $59,1 \%$ & 1.743 & $34,9 \%$ & 4.997 \\
\hline Padrasto & 228 & $4,6 \%$ & 3.034 & $60,7 \%$ & 1.735 & $34,7 \%$ & 4.997 \\
\hline Madrasta & 8 & $0,2 \%$ & 3.218 & $64,4 \%$ & 1.771 & $35,4 \%$ & 4.997 \\
\hline Cônjuge & 567 & $11,3 \%$ & 2.689 & $53,8 \%$ & 1.741 & $34,8 \%$ & 4.997 \\
\hline Ex-cônjuge & 176 & $3,5 \%$ & 3.061 & $61,3 \%$ & 1.760 & $34,2 \%$ & 4.997 \\
\hline Namorado(a) & 224 & $4,5 \%$ & 3.034 & $60,7 \%$ & 1.739 & $35,2 \%$ & 4.997 \\
\hline
\end{tabular}




\begin{tabular}{|c|c|c|c|c|c|c|c|}
\hline Ex-namorado(a) & 42 & $0,8 \%$ & 3.188 & $63,8 \%$ & 1.707 & $35,2 \%$ & 4.997 \\
\hline Filho(a) & 141 & $2,8 \%$ & 3.099 & $62,0 \%$ & 1.757 & $32,9 \%$ & 4.997 \\
\hline Irmão(a) & 148 & $3,0 \%$ & 3.092 & $61,9 \%$ & 1.757 & $33,7 \%$ & 4.997 \\
\hline Amigos/Conhecidos & 779 & $15,6 \%$ & 2.573 & $51,5 \%$ & 1.645 & $35,4 \%$ & 4.997 \\
\hline Desconhecido(a) & 483 & $9,7 \%$ & 2.831 & $56,7 \%$ & 1.683 & $35,3 \%$ & 4.997 \\
\hline Cuidador(a) & 15 & $0,3 \%$ & 3.215 & $64,3 \%$ & 1.767 & $35,4 \%$ & 4.997 \\
\hline Patrão/Chefe & 7 & $0,1 \%$ & 3.225 & $64,5 \%$ & 1.765 & $35,3 \%$ & 4.997 \\
\hline Relação Institucional & 21 & $0,4 \%$ & 3.208 & $64,2 \%$ & 1.768 & $35,4 \%$ & 4.997 \\
\hline Agente da Lei & 10 & $0,2 \%$ & 3.207 & $64,2 \%$ & 1.780 & $35,6 \%$ & 4.997 \\
\hline Outros Vínculos & 379 & $7,6 \%$ & 2.853 & $57,1 \%$ & 1.765 & $35,3 \%$ & 4.997 \\
\hline
\end{tabular}

*Cada variável possui um total diferente por se tratarem de variáveis independentes. Fonte: Ministério da Saúde/SVS - Sistema de Informação de Agravos de Notificação (SINAN) (2021).

A associação a suspeita do uso de álcool por parte do agressor com os casos de violência doméstica se mostrou positiva em $23,8 \%$ dos casos, contra $24,7 \%$ que não tinham relação alguma e 51,5\% que não possuíam essa informação discriminada na ficha de notificação (Figura 2).

Figura 2. Percentual de casos de violência doméstica em que há suspeita do consumo de álcool por parte do agressor em Sergipe, entre 2009 e 2019, de acordo com variáveis da ficha de notificação do SINAN.

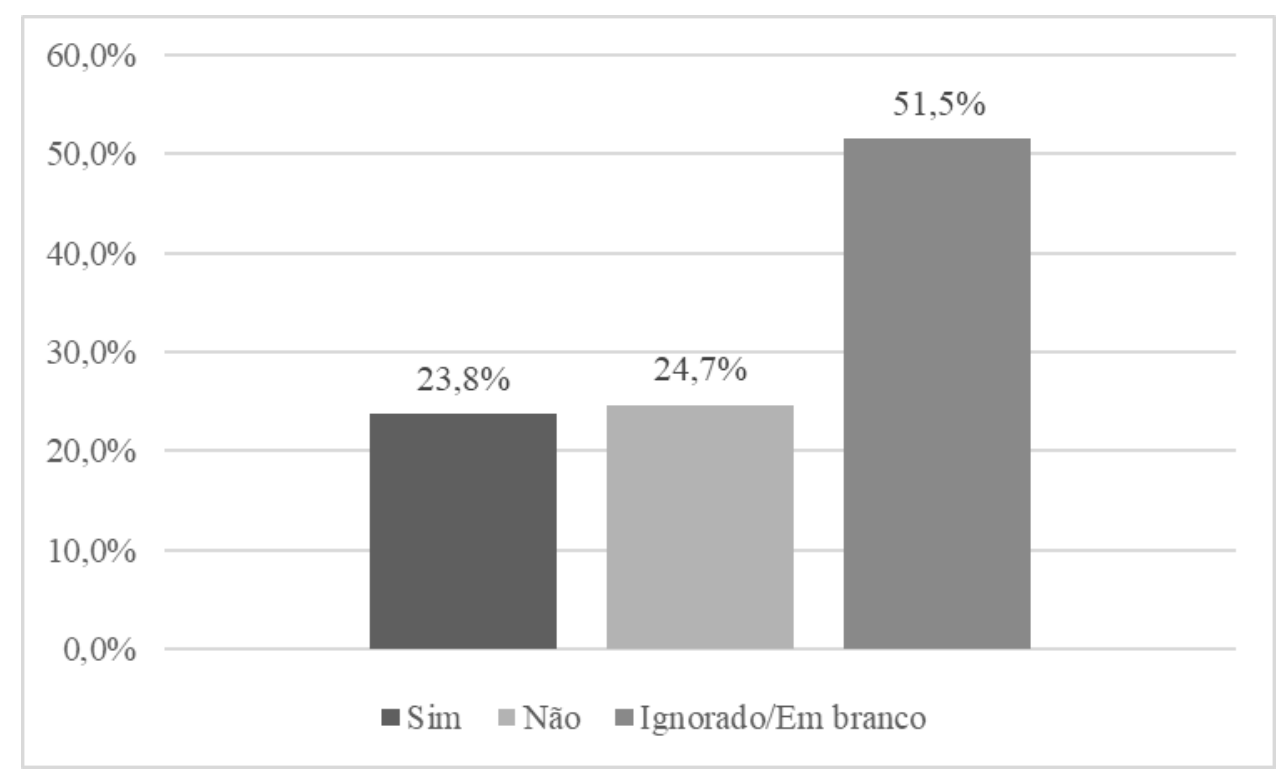

Fonte: Ministério da Saúde/SVS - Sistema de Informação de Agravos de Notificação (SINAN) (2021).

Por fim, do total de casos, os dados referentes ao encaminhamento e evolução do atendimento pelo profissional de saúde demonstram que $1.413(28,3 \%)$ pacientes tiveram encaminhamento ambulatorial, enquanto $114(2,3 \%)$ tiveram desfecho de internação hospitalar e os demais casos não tinham informações sobre encaminhamento $(1,3 \%$ não se aplica e $68,1 \%$ ignorado ou em branco). Quanto à evolução do caso, os dados disponíveis no SINAN mostraram que 831 (16,6\%) das vítimas receberam alta no momento da notificação, 69 (1,4\%) evadiram da unidade de atendimento, apenas $4(0,1 \%)$ das fichas do SINAN evoluíram em óbito por violência e 81,9\% dos casos ficaram sem essa informação (ignorado/em branco) (Tabela 3). 
Tabela 3. Evolução e encaminhamento dos casos de violência doméstica contra a mulher em Sergipe, entre 2009 e 2019 , de acordo com variáveis da ficha de notificação compulsória do SINAN (N =4.997).

\begin{tabular}{lrr}
\hline Evolução do caso & Frequência & $\%$ \\
\hline Alta & 831 & 16,6 \\
Evasão/fuga & 69 & 1,4 \\
Óbito por violência & 4 & 0,1 \\
Ignorado/Em branco & 4.093 & 81,9 \\
\hline Encaminhamento da Pessoa Atendida & & 1.413 \\
\hline Encaminhamento Ambulatorial & 114 & 28,3 \\
Internação Hospitalar & 67 & 2,3 \\
Não se aplica & 3.403 & 1,3 \\
Ignorado/Em branco & 68,1 \\
\hline
\end{tabular}

Fonte: Ministério da Saúde/SVS - Sistema de Informação de Agravos de Notificação (SINAN) (2021).

\section{Discussão}

O presente estudo é original em coletar os dados de notificação de violência doméstica feminina no estado de Sergipe, presentes no banco de dados do Sistema de Informação de Agravos de Notificação (SINAN). O uso do SINAN é importante para atender as demandas e entender melhor o perfil de morbidade do Estado. Entretanto o sistema ainda possui limitações e precisa de constantes atualizações disponibilizadas pelo Ministério da Saúde (Araújo \& Silva, 2015).

Os dados inicias desse estudo mostraram a prevalência de indivíduos do sexo feminino como vítimas da violência doméstica, embora também existem muitos casos no sexo masculino. É importante destacar que, ao comparar os dados de idade com sexo na plataforma do DATASUS, as faixas etárias de crianças e adolescentes apresentam grande prevalência em ambos os sexos, com predomínio feminino. Já na vida adulta, somente as mulheres apresentam elevados números de notificação. A literatura define que violência doméstica pode abranger mulheres e homens como possíveis vítimas, entretanto os conceitos de patriarcado põem a mulher num regime de dominação-exploração com o objetivo de manter o poder masculino (Saffioti, 2004). A literatura destaca que uma mulher pode praticar violência física contra seu companheiro, mas a mulher, enquanto categoria social, não tem um projeto de dominação-exploração dos homens como o presente no patriarcado. Já em relação às crianças e adolescentes, as mulheres costumam exercer a função patriarcal por delegação, dessa forma, mães, professoras e babás costumam ser perpetuadoras da violência doméstica, o que explica os elevados índices de notificação nas faixas etárias de crianças e adolescentes de ambos os sexos (Saffioti, 2001).

Ao avaliar a idade dos casos dos casos notificados, observamos o destaque das faixas etárias que englobam crianças menores de 10 anos e adolescentes e jovens de 10 a 19 anos, respectivamente em terceiro e segundo lugar. As mulheres adultas de 20 a 59 anos representam uma faixa etária mais abrangente e ficaram em primeiro lugar. Garbin et al. (2006) encontraram uma distribuição da vitimação de mulheres de praticamente todas as idades, com destaque para a faixa etária de 0 a 15 anos (51,5\%), seguida das mulheres de 30 a $45(18,2 \%)$ e das jovens de 15 a 30 anos (5,1\%). O grande número de casos em menores de idade pode ser explicado pela legislação sobre maus tratos ser melhor regularizada há mais tempo no artigo de número 136 do Código Penal, que garante que as autoridades policiais instaurem inquérito policial e punam culpados (Brasil, 2021). O mesmo não ocorre nos casos de mulheres adultas que, até o ano de 2015, tinham a faculdade de denunciar ou não os abusos que sofriam, e muitas vezes elas optavam por desistir de levar o processo adiante por medo, vergonha, dependência financeira e afetiva, ou por desacreditarem nas instituições jurídicas (Garbin et al., 2006). Com a da Lei do Feminicídio de 2015, a pena nesses casos foi aumentada e foi instaurado o caráter compulsório do inquérito policial, independentemente de a vítima querer ou não manter a denúncia contra o agressor (Brasil, 2015). 
O resultado encontrado nos estudos de Gadoni-Costa et al. (2011) e Miranda et al. (2010) foi de médias de idade de $36,9 \pm 13,1$ anos e 33,4 $\pm 7,6$, respectivamente. É importante destacar que esses estudos usados para comparação foram feitos com dados coletados em serviços especializados de violência contra a mulher. O mesmo não ocorre com os dados de notificação compulsória, que abrangem a ação profissionais de saúde atuantes em qualquer serviço, incluindo os não especializados, o que poderia explicar essas diferenças amostrais. Pestana et al. (2021) encontrou maior prevalência de notificações de mulheres vítimas de violência doméstica entre as faixas etárias de 20-29 e 30-39 em Pernambuco, mostrando que esses dados dependem da região e do preparo da equipe para preencher a ficha de notificação compulsória.

Com relação à maior frequência de agressões sofridas por mulheres de 00 a 19 anos, um estudo também realizado em Sergipe mostrou que a proporção de jovens nesta faixa etária com registro de violência sexual no Instituto Médico Legal de Sergipe e na Maternidade Nossa Senhora de Lourdes, referências para esses casos em Sergipe, corresponde a 86,1\% de todos os casos femininos (Andrade et al., 2021).

Quando avaliamos os dados de raça/etnia encontrados, temos no presente trabalho uma maior parcela que se autodeclara parda (44,8\%), seguida de 10,9\% de mulheres brancas. Isso está de acordo com o trabalho de Ferreira et al. (2016), que encontraram uma porção de 47,2\% de mulheres pardas e $21,3 \%$ de mulheres brancas atendidas em uma unidade de proteção especial de mulheres vítimas de violência no estado do Ceará. O mesmo padrão não foi encontrado por Vieira, Perdona \& Santos (2011) ao avaliarem mulheres atendidas em Unidades Básicas de Saúde em uma cidade do interior de São Paulo, onde encontraram prevalência de mulheres brancas $(55,6 \%)$ e pardas $(30,7 \%)$. Essa diferença regional pode vir do perfil das populações estudas, visto que Sergipe e Ceará são mais semelhantes por estarem localizados na região Nordeste e apresentarem um perfil socioeconômico próximo.

Já em relação à escolaridade, é possível observar que os poucos anos de estudo estão muito relacionados com os episódios de violência doméstica, com maior número de registros válidos de pessoas com até 8 anos de ensino. Gadoni-Costa et al. (2011) observaram que, das mulheres atendidas no setor de Psicologia da Delegacia para a Mulher da região metropolitana de Porto Alegre, cerca de 53,7\% delas não possuíam o ensino fundamental completo (oito anos de formação). Vieira et al. (2011) e Sebaldeli et al. (2021) também registraram que 48,2\% e 45,4\% de mulheres, respectivamente, tinham até oito anos de estudo formal.

Vale ressaltar, entretanto, que, por se tratar de uma amostra com grande contingente de crianças em idade escolar, os números se tornam de difícil análise. Isso é observado nos casos que foram assinalados como "Não se aplica", pois todos eles estavam na faixa etária menor de 10 anos e não possuíam informações de escolaridade. Somente separando as faixas etárias que poderia ser feita uma análise mais fidedigna. Entretanto, as ferramentas da plataforma do DATASUS ainda possuem algumas limitações. Outro exemplo disso são os dados ocupação e situação conjugal, que estão presentes na ficha de notificação compulsória, mas não estão disponíveis na plataforma do DATASUS, impossibilitando o acesso a essas informações sociodemográficas.

É importante também destacar que existe muita subnotificação das variáveis raça/cor e escolaridade, com informações ignoradas ou em branco em 49,5\%. O que denota que tais informações não foram priorizadas pelos profissionais da saúde notificantes, mesmo sendo dados importantes para mensurar as desigualdades sociais no universo da violência doméstica.

Quanto à reincidência, falhas no preenchimento foram recorrentes, mas, nos casos corretamente assinalados, 48,6\% corresponderam a violência de repetição. Isso mostra um caráter sistemático dessa violência, na qual boa parte das vítimas já foram agredidas anteriormente. Segundo dados do Sistema de Vigilância de Violências e Acidentes (VIVA), foi registrado que 39,7\% das mulheres mortas por consequência da violência em 2008 já haviam sofrido violência anteriormente (Garcia et al., 2015). Outro estudo relatou que $67,0 \%$ das mulheres que foram vítimas de tentativa de homicídio por seus parceiros já haviam sido agredidas anteriormente, seja por ocasionais tapas e empurrões, até frequentes lesões que ameaçavam a vida das mesmas 
(Nicolaidis et al., 2003). Esse caráter de reincidência denota a perpetuação de atos violentos de ameaças, intimidação, violência sexual e física que muitas vezes começam de forma mais branda e podem culminar no óbito feminino - o chamado feminicídio.

O principal local de ocorrência foi a própria residência da vítima, o que favorece a "invisibilidade" dessa problemática, visto que vivemos uma cultura de que "em briga de marido e mulher, não se mete a colher" e as questões do foro íntimo não são questionadas pela sociedade em geral. Este dado foi semelhante ao encontrado no Rio de Janeiro entre 2008 e 2017, com a residência (53,6\%) sendo o local de maior ocorrência de violência contra as mulheres (Duffrayer et al., 2021).

Os casos de violência física foram a tipologia mais notificada neste período estudado, seguido pela violência sexual, cujo principal tipo foi o estupro. Logo após, foram notificados muitos casos de violência psicológica e de negligência. Estudos mundiais divulgados pela Organização Mundial de Saúde (OMS) encontraram que 22,0 a 30,0\% das mulheres reportam violência física, sexual ou ambas por seus parceiros pelo menos uma vez na vida (World Health Organization, 2021). Esses dados da OMS foram obtidos com análise da situação em vários países pelo mundo e demonstraram também que comportamentos controladores e emocionalmente abusivos também são comuns nesses casos. Para Pierotti, d'Oliveira e Terra (2018), a violência psicológica é muito mais frequente e danosa que agressões físicas que elas sofriam. Já para Duffrayer et al. (2021), a violência física $(58,9 \%)$ foi a principal etiologia, seguida da psicológica/moral $(22,3 \%)$.

A força física e a ameaça representaram os principais meios de agressão usados para perpetuar os atos violentos. Dados semelhantes foram encontrados em estudo que entrevistou mulheres atendidas em unidade de proteção especial a vítimas de violência, evidenciando que 40,0\% dessas mulheres foram agredidas por meio de força física e $15,0 \%$ por meio de agressão verbal/ameaça (Ferreira et al., 2016). Somando a isso, Garbin et al. (2006), ao analisarem lesões descritas em inquéritos policiais de lesão corporal e maus-tratos, encontraram que 60,0\% das lesões foram por agente contundente, em especial por se tratarem de espancamentos. Eles ainda destacaram a preferência por golpes dados na região da cabeça e pescoço, seguida dos membros superiores e inferiores.

Quanto aos suspeitos da agressão, nessa amostra foi observada um destaque para amigos e conhecidos, seguidos dos cônjuges, evidenciando que os principais agressores estão no convívio das vítimas. Também pais e mães foram importantes agressores e isso é interessante de se observar, principalmente porque a amostra estudada tem grande parcela de crianças e adolescentes e seus pais acabam perpetuando a violência doméstica. No estado do Ceará, entre 2009 e 2018, o principal agressor correspondeu ao cônjuge/ex-cônjuge, seguidos da mãe, do pai e de amigos (Leitão et al., 2021). Um estudo destacando os casos de violência doméstica no Brasil discriminou o perfil do agressor com base na faixa etária das vítimas, assim ele observou que, na infância, os principais agressores são mãe e pai, nos adolescentes, desconhecidos e namorados ganham destaque junto com os genitores, jovens e adultos são vitimados principalmente por cônjuges e ex-cônjuges, e os idosos sofrem por parceiros, pais e irmãos (Waiselfisz, 2013).

Outro dado presente nas notificações é a suspeita de uso de álcool por parte do agressor, que está presente numa boa parcela dos casos, o que está de acordo com a literatura (Pan American Health Organization, 2008; Vieira et al., 2014). Entretanto, essa é outra variável pouco assinalada durante o preenchimento, com mais da metade das fichas sem essa informação. Outra questão é que informações de uso de outras substâncias psicoativas não possui local próprio de registro na ficha de notificação, impedindo a obtenção dessa informação.

Quanto à evolução e encaminhamento dos casos, boa parte recebeu alta ou teve encaminhamento ambulatorial. Embora as taxas nacionais de feminicídio sejam bem elevadas em relação a padrões internacionais, as fichas de notificação de violência doméstica apresentaram apenas 4 casos de evolução para óbito no período de 2009 a 2019. Isso pode ser explicado pela existência de ficha própria de mortalidade com dados divulgados pelo Sistema de Informação sobre Mortalidade (SIM), também disponível no DATASUS. No período de 2009 a 2013, as taxas de homicídios de mulheres ficaram entre 4,4 a 4,8 
casos a cada 100.000 habitantes em todo o Brasil, e, em Sergipe, foram contabilizados de 32 a 62 casos por ano nesse mesmo período (Waiselfisz, 2013). Essa falta de conexão entre os dados de violência doméstica e mortalidade feminina mostram que ainda existe muito a se melhorar na rede de informação do SUS, para que seja possível criar mecanismos e programas voltados a diminuição desse grave problema de saúde pública.

A falta de preparo dos profissionais da saúde parece ser um dos principais obstáculos a serem transpostos. Baixos índices de notificação e mau preenchimento das fichas de notificação geram dados pouco fidedignos e que subestimam o problema da violência contra a mulher. Durante a formação profissional, pouco ou quase nada é discutido sobre o fluxo de notificação e dos instrumentos necessários para esse procedimento, tanto na graduação, como na pós-graduação e capacitações dos serviços de saúde. Falta preparo técnico e emocional para identificação da violência e dos sinais de alerta; existe o medo de represália por parte do agressor; ocorre uma falta de retaguarda de uma rede de proteção e o isolamento do profissional de saúde, que se vê numa situação complexa, sem ter com quem dividir os seus questionamentos (Assis et al., 2012; Garbin et al., 2006).

\section{Conclusão}

A violência doméstica em Sergipe atinge principalmente mulheres de 20 a 59 anos, de raça parda e com nível de escolaridade compatível com 5 a 8 anos de estudo. Elas são vitimadas por pessoas do seu convívio diário dentro de suas casas, com amigos, companheiros, desconhecidos, mães e pais como os principais suspeitos. Os principais tipos de violência foram a física, a sexual (em especial o estupro) e a psicológica, e a força física foi o principal meio de agressão, mostrando que os atos mais violentos que levam à busca de ajuda especializada e posterior notificação. A suspeita do uso de álcool pelos agressores e a recidiva se mostraram presentes no estudo. E a evolução com alta e encaminhamento ambulatorial também foram destaque no perfil dos casos notificados. Por fim, os índices de subnotificação e mal preenchimento das fichas de notificação apresentaram-se altos.

Estudos de campo sobre a violência doméstica em Sergipe são necessários, principalmente para reduzir a dificuldade ao acesso de dados mal preenchidos e subnotificados.

\section{Referências}

Alonso, M. del C. F. (2015). Compromiso de la atención primaria ante la violencia de género. ¿Hemos superado el reto? Atención Primaria, 47(3), 129-130. https://doi.org/10.1016/j.aprim.2015.02.001

Andrade, R. L. B. de, Sales, L. G. D., Jesus, C. V. F. de, Ferrari, Y. A. C., Santana, V. R. de, Nardelli, M. J., Prado, L. O. M., Reis, F. P., Mendonça, A. K. R. H. \& Lima, S. O. (2021). Violência sexual contra crianças e adolescents do sexo feminino: Uma questão de saúde pública. Research, Society and Development, 10(3). http://dx.doi.org/10.33448/rsd-v10i3.12864

Araújo, M. M. \& Silva, C. G. (2015). A importância do sistema de informação de agravos de notificação - SINAN para a vigilância epidemiológica do Piauí. Revista Interdisciplinar Ciências e Saúde - RICS, 2(3), 25-29. https://revistas.ufpi.br/index.php/rics/article/view/2046/2317

Assis, S. G. de, Avanci, J. Q., Pesce, R. P., Pires, T. de O., \& Gomes, D. L. (2012). Notificações de violência doméstica, sexual e outras violências contra crianças no Brasil. Ciência \& Saúde Coletiva, 17(9), 2305-2317. https://doi.org/10.1590/S1413-81232012000900012

Brasil. Casa Civil. (2003). Lei $\mathrm{n}^{\mathrm{o}} 10.778$, de 24 de novembro de 2003. Diário Oficial da União. Casa Civil, 2003. http://www.planalto.gov.br/ccivil_03/leis/2003/110.778.htm

Brasil. Ministério da Justiça. (2010). Norma técnica de padronização das delegacias especializadas de atendimento às mulheres — DEAMS. Brasília: Diário Oficial da União. Ministério da Justiça, Secretaria de Políticas para as Mulheres, 2010.2 https://assets-compromissoeatitudeipg.sfo2.digitaloceanspaces.com/2012/08/MJ-2010-Norma-Tecnica-Padronizacao-DEAMs.pdf

Brasil. Ministério da Saúde. Biblioteca Virtual em Saúde. (2021b). Ficha de Notificação de Violência Doméstica. http://bvsms.saude.gov.br/bvs/folder/ficha_notificacao_violencia_domestica.pdf

Brasil. Ministério da Saúde. Departamento de Informática do SUS. (2021a). DATASUS. http://www2.datasus.gov.br/DATASUS/index.php

Brasil. Secretaria-Geral. (2006). Lei $\mathrm{n}^{\mathrm{o}}$ 11.340, de 7 de agosto de 2006. Diário Oficial da União. Secretaria-Geral, 2006. http://www.planalto.gov.br/ccivil_03/_ato2004-2006/2006/lei/111340.htm 
Brasil. Secretaria-Geral. (2015). Lei $\mathrm{n}^{\circ}$ 13.104, de 9 de março de 2015. Diário Oficial da União, Secretaria-Geral, 2015. http://www.planalto.gov.br/ccivil_03/_ato2015-2018/2015/lei/113104.htm

Duffrayer, K. M., Mota, C. P. da, Silva, J. L. L. da, Messias, C. M., Moura, A. C. C. A. C. de, Silva, V. G. de F. e, Pereira, A. V. \& Silva, N. V. M. da. (2021). Perfil sociodemográfico de mulheres vítimas de violência no período de 2008 a 2017. Research, Society and Development, 10(4). http://dx.doi.org/10.33448/rsd-v10i4.13823

Ferraz, L. H. V. da C. (2009). O SUS, o DATASUS e a informação em saúde: uma proposta de gestão participativa. Rio de Janeiro: Escola Nacional de Saúde Pública Sergio. https://bvssp.icict.fiocruz.br/pdf/25885_ferrazlhvcm.pdf

Ferreira, R. M., Vasconcelos, T. B. de, Moreira Filho, R. E. \& Macena, R. H. M. (2016). Características de saúde de mulheres em situação de violência doméstica abrigadas em uma unidade de proteção estadual. Ciência \& Saúde Coletiva, 21(12), 3937-3946. https://doi.org/10.1590/1413812320152112.09092015

Gadoni-Costa, L. M., Zucatti, A. P. N. \& Dell'Aglio, D. D. (2011). Violência contra a mulher: levantamento dos casos atendidos no setor de psicologia de uma delegacia para a mulher. Estudos de Psicologia (Campinas), 28(2), 219-227. https://doi.org/10.1590/S0103-166X2011000200009

Garbin, C. A. S., Garbin, A. J. I., Dossi, A. P. \& Dossi, M. O. (2006). Violência doméstica: análise das lesões em mulheres. Cadernos de Saúde Pública, 22(12), 2567-2573. https://doi.org/10.1590/S0102-311X2006001200007

Garcia, L. P., Freitas, L. R. S. de, Silva, G. D. M. da \& Höfelmann, D. A. (2015). Estimativas corrigidas de feminicídios no Brasil, 2009 a 2011. Revista Panamericana de Salud Pública, 37(4/5), 251-257. https://scielosp.org/pdf/rpsp/2015.v37n4-5/251-257/pt

Leitão, P. R. P., Batista, J. F. C., Dantas, B. L. L., Oliveira, A. V. do N., Quezado, S. R. S. \& Silva, J. de O. M. (2021). Violência interpessoal contra a mulher no Estado do Ceará de 2009 a 2018: estudo ecológico. Research, Society and Development, 10(11). http://dx.doi.org/10.33448/rsd-v10i11.19400

Miranda, M. P. de M., Paula, C. S. de \& Bordin, I. A. (2010). Violência conjugal física contra a mulher na vida: prevalência e impacto imediato na saúde, trabalho e família. Revista Panamericana de Salud Pública, 27(4), 300-308. https://www.scielosp.org/pdf/rpsp/v27n4/a09v27n4.pdf

Nicolaidis, C., Curry, M. A., Ulrich, Y., Sharps, P., McFarlane, J., Campbell, D., Gary, F., Laughon, K., Glass, N. \& Campbell, J. (2003) Could we have known? A qualitative analysis of data from women who survived an attempted homicide by an intimate partner. Journal of General Internal Medicine, 18(10), 788-794. https://dx.doi.org/10.1046\%2Fj.1525-1497.2003.21202.x

Pan American Health Organization. (2008). Unhappy hours: alcohol and partner aggression in the America.: PAHO. https://iris.paho.org/bitstream/handle/10665.2/2829/9789275116319_Eng.pdf?sequence=12\&isAllowed=y

Pestana, J. T. da S., Santos, E. K. M. dos, Silva, A. M. de M., Rocha, C. M. da, Nascimento, G. A. do, Rodrigues, I. S., Silva, M. C. \& da, Monteiro, T. M. de Q. Epidemia invisível: perfil epidemiológico de mulheres vítimas de violência doméstica no Estado de Pernambuco entre 2015 e 2019. Brazilian Journal of Development, 7(6), 64290-64308. https://doi.org/10.34117/bjdv7n6-691

Pierotti, C. F., d'Oliveira, A. F. P. L. \& Terra, M. F. (2018). A situação de violência doméstica de gênero na atenção primária à saúde. Arquivos Médicos dos Hospitais e da Faculdade de Ciências Médicas da Santa Casa de São Paulo, 63(1), 12-18. https://doi.org/10.26432/1809-3019.2018.63.1.12

Saffioti, H. I. B. (2001). Contribuições feministas para o estudo da violência de gênero. Cadernos pagu, (16), 115-136. https://doi.org/10.1590/S010483332001000100007

Saffioti, H. I. B. (2004). Gênero, patriarcado, violência. $1^{\text {a }}$ Edição. São Paulo: Editora Fundação Perseu Abramo. https://www.mpba.mp.br/sites/default/files/biblioteca/direitos-humanos/direitos-das-mulheres/obras-digitalizadas/questoes_de_genero/safiotti_heleieth__genero_patriarcado_e_violencia_1.pdf

Sebaldeli, A. C. G., Ignotti, E., \& Hartwig, S. V. (2021). Violência contra a mulher em uma cidade da fronteira do Brasil. Research, Society and Development, 10(3). http://dx.doi.org/10.33448/rsd-v10i3.12941

Vasconcellos, M. M., Moraes, I. H. S. de \& Cavalcante, M. T. L. (2002). Política de saúde e potencialidades de uso das tecnologias de informação. Saúde em debate, 26(61), 219-235. https://docvirt.com/asp/acervo_cebes.asp?Bib=SAUDEDEBATE\&PASTA=V.26\%2C+N.61+--maio\&pesq=\&x=111\&y=21

Vieira, L. B., Cortes, L. F., Padoin, S. M. de M., Souza, I. E. de O., Paula, C. C. de \& Terra, M. G. (2014). Abuso de álcool e drogas e violência contra as mulheres: denúncias de vividos. Revista brasileira de enfermagem, 67(3), 266-372. https://doi.org/10.5935/0034-7167.20140048

Vieira, E. M., Perdona, G. da S. C. \& Santos, M. A. dos. (2011). Fatores associados à violência física por parceiro íntimo em usuárias de serviços de saúde. Revista de Saúde Pública, 45(4), 730-737. https://doi.org/10.1590/S0034-89102011005000034

Waiselfisz, J. J. (2013). Mapa da violência 2013: homicídios e juventude no Brasil. $1^{a}$ Edição. Brasília: Secretaria-Geral da Presidência da República. http://flacso.org.br/files/2020/03/mapa2013_homicidios_juventude.pdf

World Health Organization. (2021). Violence against women prevalence estimates, 2018. World Health Organization. https://www.who.int/publications/i/item/9789240022256 